\title{
Redesigning a product: Assembly, manufacture and production strategies
}

\section{Rediseño de un producto: Estrategias de ensamble, fabricación y producción}

\author{
OJEDA-ESCOTO, Pedro Agustín†*
}

Universidad Tecnológica de Aguascalientes, División de Electromecánica Industrial y Energías, Blvd. Juan Pablo II 1302 Exhacienda la Cantera, C.P. 20200, Aguascalientes, México.

ID $1^{\text {st }}$ Author: Pedro Agustín, Ojeda-Escoto / ORC ID: 0000-0001-7282-4672, CVU CONACYT ID: 50027

\begin{abstract}
In the design of a product, several factors are involved to define it as functional and is also important to clearly state its life cycle. On the other hand, the participation of the client or end user is very important for the approach of the main specification and with the purpose of conforming a product that has ample possibilities of competition in the global market. Looking for the consolidation of a new product, in the present work the redesign of a harvester (case study) was carried out. For the proposal of the new design, the reference framework is based on design for disassembly (DFD) to propose the development of the technical process and design for manufacturing (DFM) to optimize the production process. Is also presented the procedure used to structure the harvester redesign under the approach of production quality improvement and cost reduction, which helped to define a final functional configuration able to be aligned to mass production.
\end{abstract}

Redesign, New product, Production

\section{Resumen}

En el diseño de un producto intervienen varios factores para definirlo como funcional y también es importante plantear claramente su ciclo de vida. Por otro lado, la participación del cliente o usuario final es muy importante para el planteamiento de la especificación principal y con el fin de conformar un producto que tenga amplias posibilidades de competencia en el mercado global. Buscando la consolidación de un nuevo producto, en el presente trabajo se realizó el rediseño de una cosechadora (caso de estudio). Para la propuesta del nuevo diseño, el marco de referencia se basa en el diseño para el desensamble (DFD) para proponer el desarrollo del proceso técnico y el diseño para manufactura (DFM) para optimizar el proceso de producción. También se presenta el procedimiento utilizado para estructurar el rediseño de la cosechadora bajo el enfoque de la mejora de la calidad de la producción y la reducción de costos, lo que ayudó a definir una configuración funcional final capaz de alinearse con la producción en serie.

\section{Rediseño, Nuevo producto, Producción}

Citation: OJEDA-ESCOTO, Pedro Agustín. Redesigning a product: Assembly, manufacture and production strategies. Journal of Technological Operations. 2021. 5-15: 1-9

\footnotetext{
* Author Correspondence (e-mail: pedro.ojeda@utags.edu.mx).

$\dagger$ Researcher contributing as first author.
} 


\section{Introduction}

Some design models are based on the execution and evaluation stages or on the optimization of an initial alternative. In this context, the initial solution option is evaluated and improved taking into account different aspects such as: performance, cost, assembly, functionality, reliability, maintainability; which determine the information needed for the implementation of a redesign. Feedback is applied, so that the initial concept can be modified; there is a method of redesign, known as the repeat and modify paradigm. It consists of repeating a previous design process and modifying actions whenever necessary and possible according to the original design intent for new specifications.

Such repetition refers to the execution of a stored sequence of design actions performed in the original product design. On the one hand, there are many reasons to redesign a product and the design usually derives from similar products, and on the other hand, there are many reasons to redesign a product and the design usually derives from similar products, focusing its study on which redesign is an important part in the process of developing a new product [1].

Design for Disassembly is a product design technique to be disassembled and to facilitate maintenance, repair, recovery and reuse of components and materials, reduce environmental impact and increase the end-oflife value of products, and is necessary to support an organization's current needs to accelerate innovative product development cycles combined with products. DFD is a necessary condition for products to be economically recycled, improving the processes of reuse and re-manufacturing of components and materials (for geometry optimization issues), extending the useful life of products and components can be disassembled to enable maintenance, improve serviceability and affect end-of-life [2].

Manufacturing takes raw materials and transforms them into useful products through the use of various processes. Generally, this process contains multiple steps including product design, material selection, material processing, manufacturing, packaging, etc.
The general rules of DFM consist of designing the assembly with a minimum number of parts, standard parts, modular design and multifunctional parts, making parts standard for multiple products, maximizing surface roughness and tolerance, avoiding secondary processes, using materials that are easy to manufacture, minimizing part handling, and establishing design and form guidelines. These rules of thumb focus on the cost and manufacturability of the process, leading to uniform/standardized products [3].

This article presents the procedure and results of the redesign of a harvester (case study) structured with DFD and DFM criteria under the approach of production quality improvement and cost reduction. On the other hand, the results obtained from the comparative and conceptual analysis of the harvester to optimize the final architecture are reported. Finally, the strategies defined to align manufacturing with production are mentioned.

\section{Reference Framework}

The research presented in this article is mainly based on DFD to propose the development of the technical process and DFM to optimize the production process.

\subsection{Design for disassembly}

DFD is a well-known target design methodology that enables easy separation of components in industrial products. It involves the selection and use of appropriate materials, the design of components and product architecture, and the selection and use of joints, connectors and fasteners that can be easily disassembled. DFD makes the component disassembly plan simple and efficient, and should be considered, in particular, for high quality/value components.

An investigation analyses the types of connections between components, the layout of components (product architecture), the removal directions and the first component to be disassembled to minimize time. Another step in this direction is the ability to recognize the type of mechanical connections between components in order to generate an optimal disassembly sequence directly from the CAD model of the product. 
Different algorithms have been developed to solve disassembly sequence planning, i.e., the determination of the disassembly sequence of components using combinatorial structure models. Although all these proposed methods are very interesting to solve the sequence planning problem, they do not provide quantitative results to measure the disassemblability of the products [4].

Most research has adopted disassembly time as the measure for evaluating product disassembly. Time is considered the most important criterion for selecting the best disassembly sequence, since a sequence based on this requires the least time and therefore the least cost. Time-based rankings present a realistic view of the disassembly difficulty of a proposed design and can be used to assist management in making "make or buy" decisions. For most products, a selected part can be disassembled from two or more different directions. Each route may have a different disassembly result. An optimal disassembly sequence is required to determine the shortest possible route to the core. In terms of remanufacturing, prioritizing the recovery of high-value cores over other nonremanufacturable parts of a product is essential to ensure a cost-effective disassembly process $[5,6]$.

DFD is a necessary condition for products to be economically recycled by improving component and material reuse and remanufacturing processes, extending the life of products and components. Maintenance can be simpler and the result of all these improvements results in less waste of raw materials and energy and better performance in terms of assembly, testing, procurement, shipping, delivery, service, time to market and customer satisfaction and evaluation life cycle [7]. The advantages of using DFD are that the company's core product can be recovered, metals can be separated without contaminating them, process quality can be improved, removable non-metallic parts can be reprocessed, and it allows companies to take a product from the end of its life cycle to the beginning. In today's challenging global marketplace, the increase in product landfills has driven regulatory and voluntary recycling and reuse initiatives around the world. According to this guideline, more than $50 \%$ of the product must be recycled. Consequently, manufacturers need to be more responsible with the end-of-life of their products (Figure 1) [8].

\subsection{Design for manufacturing}

Design for manufacturing uses information of many types such as: drawings, product specifications and design alternatives, a detailed understanding of the production and assembly processes, and an estimation of costs and production volumes, to achieve its ultimate goal, which is to obtain a high quality item with the best use of resources. Therefore, the collaboration of members of the development team, as well as external experts, is necessary [9].

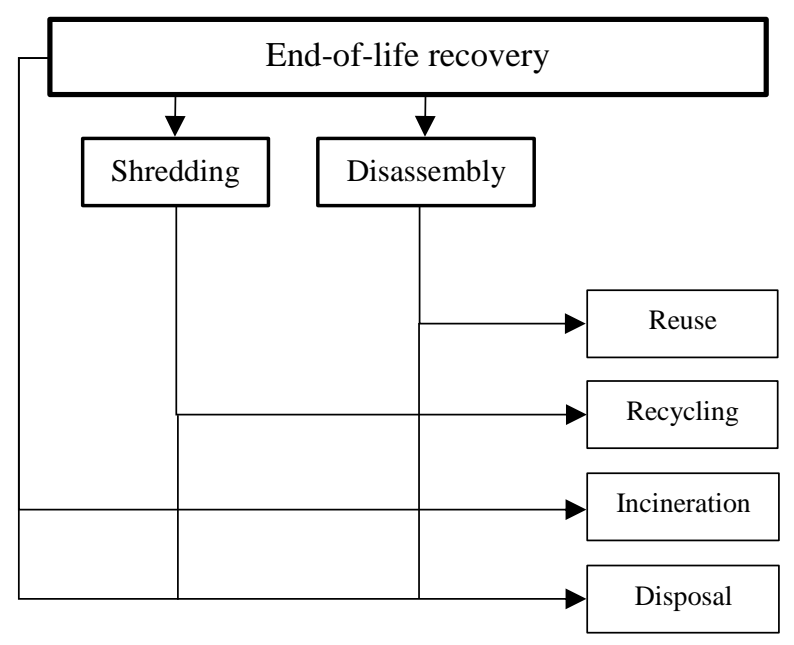

Figure 1 End-of-life product treatment options Source: Justel [8]

For the application of DFM in general, i.e., without specifications for a process, the following elements can be considered: 1 . estimate manufacturing cost, 2 . reduce component cost, 3. reduce assembly cost, 4 . reduce production cost, 5 . consider the impact of DFM decisions on other factors. Figure 2 shows the proposed general design for manufacturing methodology. The objective of using design for manufacturability applied to a particular process is to design products that are easy to maintain, reliable, shorter in time and simpler, i.e., less costly to manufacture, while maintaining product quality. To achieve the goal, there are some principles that the design team should keep in mind [10]:

\section{- $\quad$ Reduce the total number of parts \\ - Develop a modular design \\ - Use standardized materials and components \\ - Design multifunctional parts \\ - $\quad$ Design for ease of fabrication \\ - $\quad$ Avoid separate parts \\ - $\quad$ Minimize handling operations}

OJEDA-ESCOTO, Pedro Agustín. Redesigning a product: Assembly, manufacture and production strategies. Journal of Technological Operations. 2021 
- Use wide tolerances

- $\quad$ Minimize the number of operations

- $\quad$ Avoid secondary operations

- Redesign components to eliminate process steps

- Minimize operations that do not add value.

- Design for process

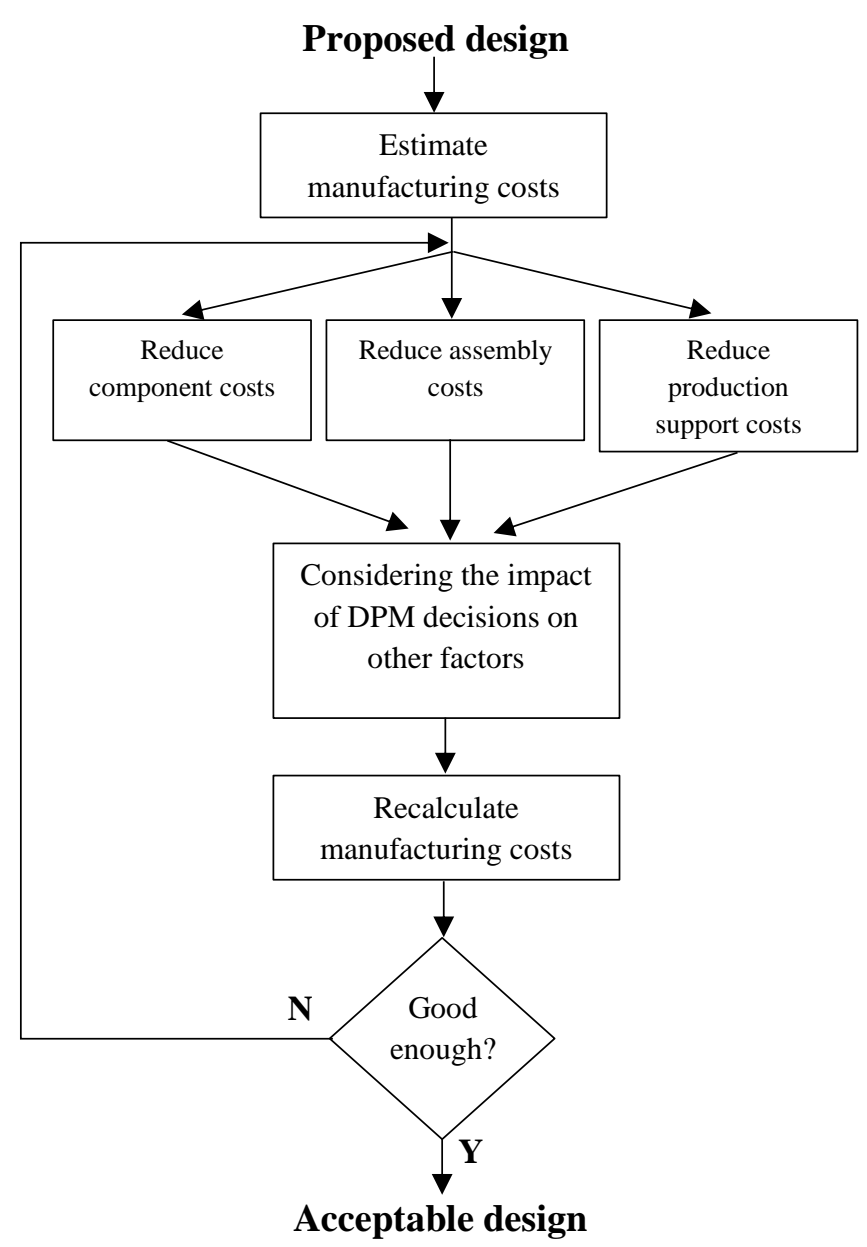

Figure 2 DFM Methodology

Source: Ulrich [9]

Before making the process selection, is necessary to make some considerations about the factors that affect process selection, such as: a. Material factors, specifically mechanical and physical properties, b. Geometric factors, including part shape, size and weight, and part tolerances and surface finishes, c. Production factors, including time to market and quantity and rate of production

\section{Investigation procedure \\ 3.1 Development procedure}

The development of any research consists of extracting the information following a methodology, the architecture of the product in question and the procedural details of the product in order to understand it.
Figure 3 presents the methodology proposed for the development of this work. The following is a very general presentation of the main activity of each of the phases of the methodology used:

\section{- $\quad$ New product}

Product systematization (specification development): Conceptualization of the final product architecture; Configuration analysis: Component assembly and disassembly testing stage; Comparative analysis: Analysis performed to define the new forage harvester concept.

\section{$-\quad$ Redesign}

Manufacturing: Implementation of manufacturing processes and continuous improvement; Design and engineering costs: Cost analysis in the design and manufacturing phases; Quality and Service: Analysis and implementation of quality conditions for the application of the manufacturing processes.

\section{- $\quad$ Final verification}

Architecture detailing, analysis of FEA results and first phase of functional testing.

\section{$-\quad$ Testing}

Second phase of functional testing under real operating conditions.

\section{- Production}

Alignment of product manufacturing with final production taking into account some strategies. 


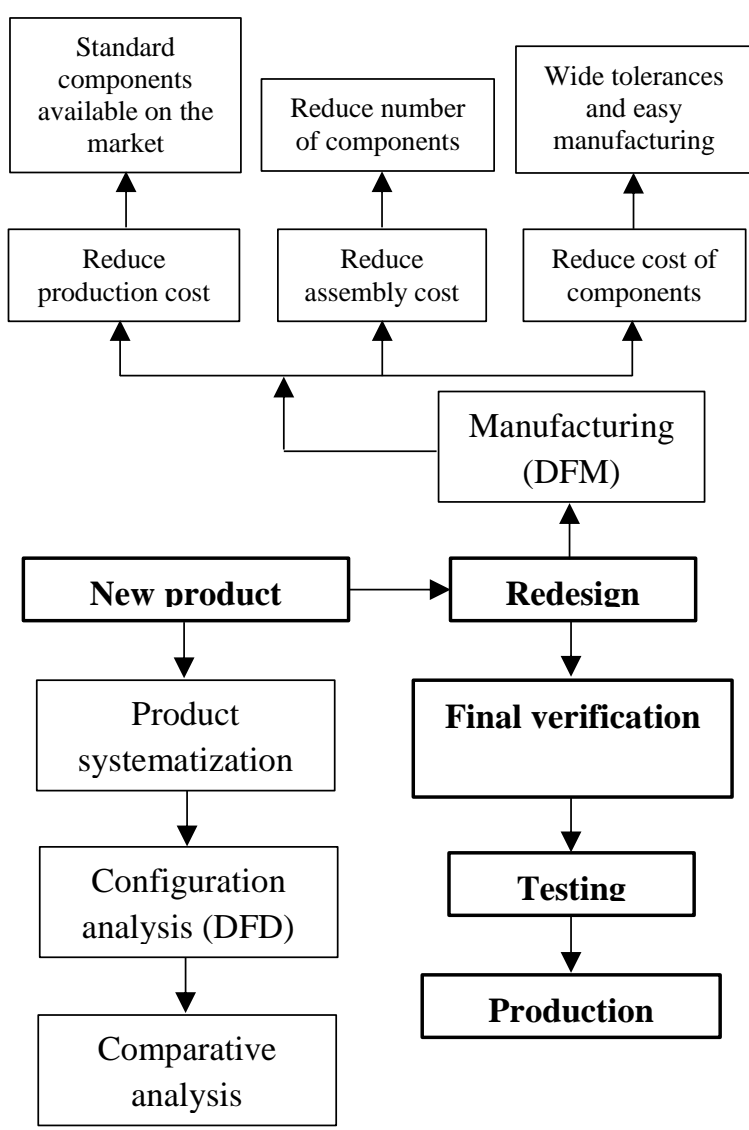

Figure 3 Methodology and research proposal Source: Own Production

\subsection{Proposed solution}

To define the new harvester design, the following approach was considered to improve production quality and reduce costs; based on this approach, several configurations were proposed and reviewed to solve the problem under study. Several configurations were conceptualized taking into account the defined approach and finally the final harvester architecture was generated (see Figure 4).

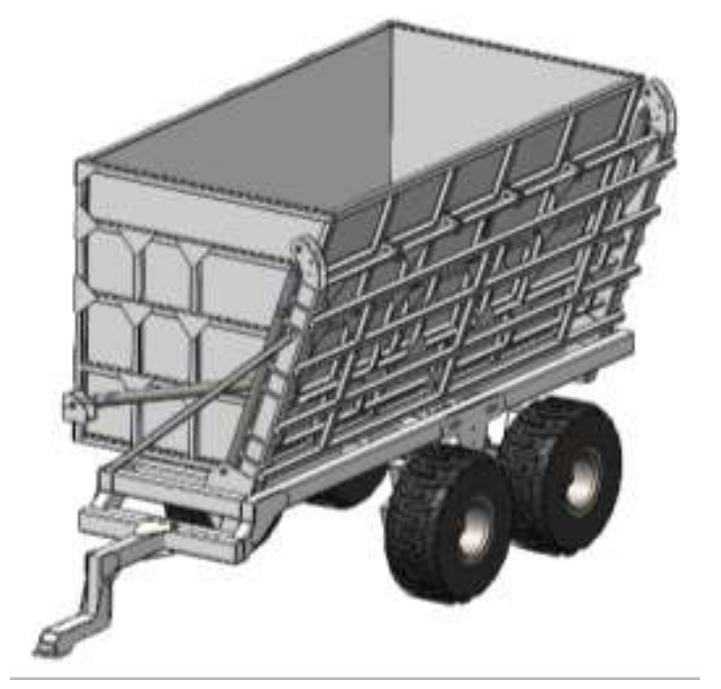

Figure 4 Final solution proposal Source: Own Production

\subsection{Geometric optimization and configuration analysis}

Two paths were followed for geometry optimization: on the one hand, some subassemblies were optimized using DFD criteria (Figure 5); and on the other hand, finite element analyses were performed to validate and optimize (for assembly purposes) such geometry. The mesh of the models was generated from the existing dimensional relationships between the components of the assembly and the load conditions proposed for the analysis were determined from the stresses that occur in the normal work of the harvester (see Figure 6).

The finite element analysis (FEA) was carried out in several stages, in each of which different criteria were used for the analysis and several stress application zones were defined according to the normal work performed by the harvester. Figure 7 shows the results obtained from the analyses performed.
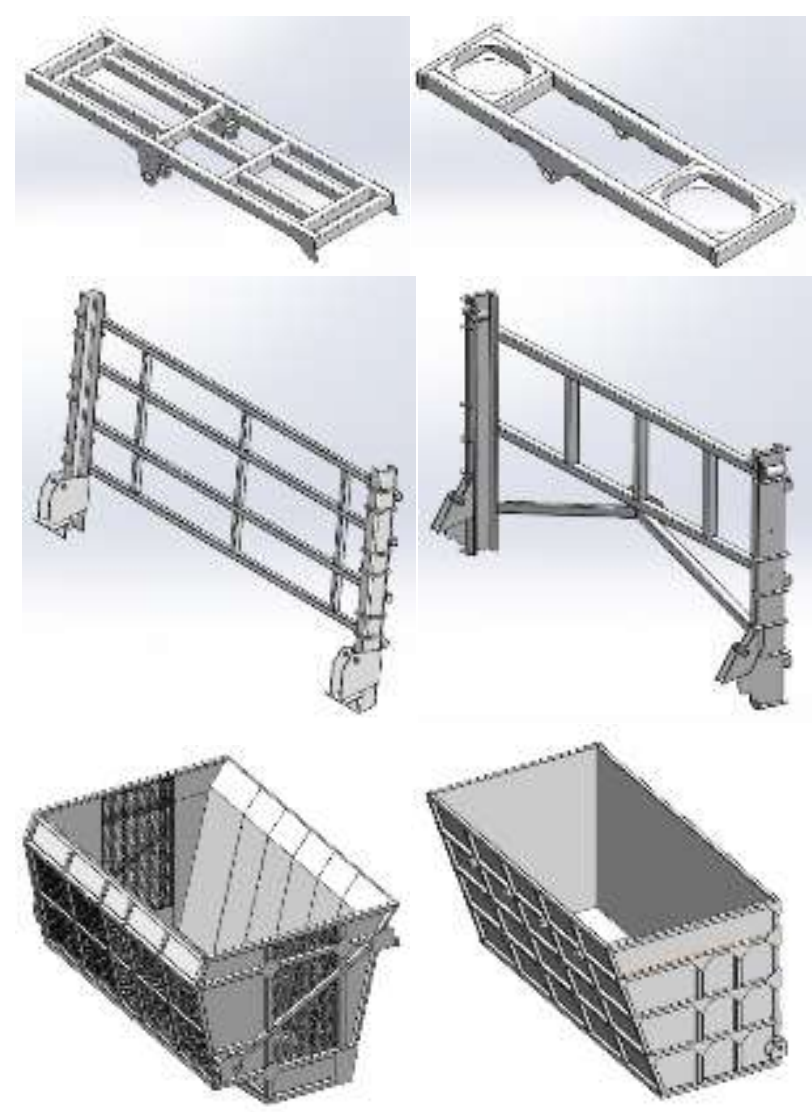

Figure 5 Optimization of sub-assemblies under DFD criteria (left column: first prototype; right column: geometry optimization)

Source: Own Production 

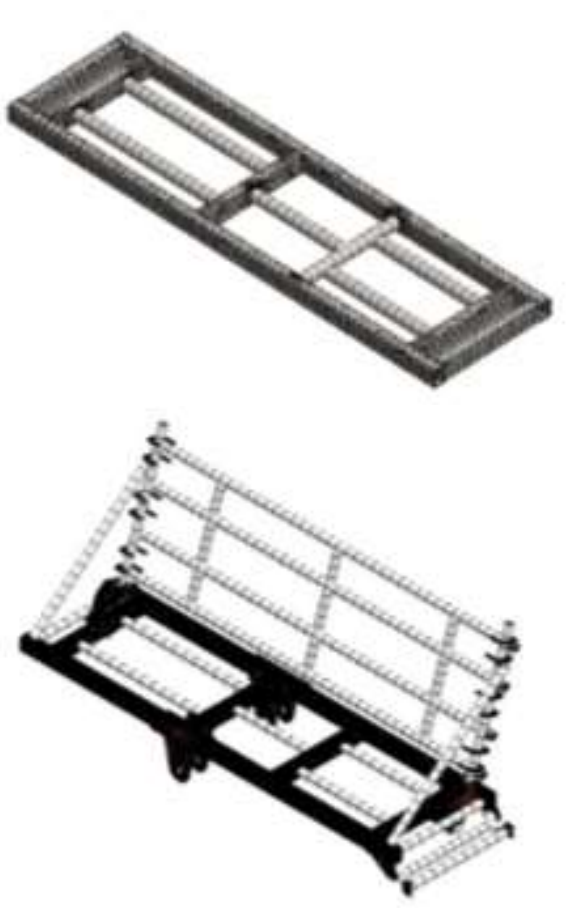

Figure 6 Meshing of functional models Source: Own Production
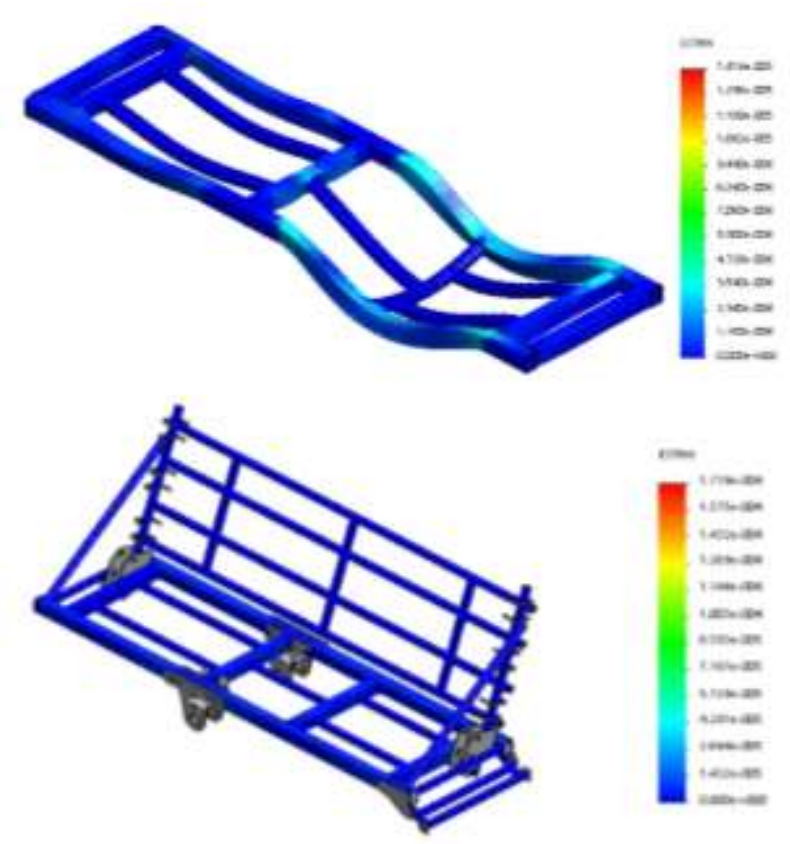

Figure 7 FEA Results

Source: Own Production

\section{Results}

\subsection{Analysis and discussion}

The stress study carried out on the harvester model showed that each of its component elements had stress magnitudes lower than those allowed by the elastic limit of the material. It was even possible to optimize some elements and comply with the design criteria taken into account to define the final architecture.
The improvements obtained in the harvester redesign process yielded the following routes, which are directly linked to the DFD and DFM analyses:

1. Characterization of geometry to reduce the final weight of the product: once the manufacture of the prototype was completed, an approximate reduction of $29 \%$ of the total weight of the harvester was obtained.

2. Improved quality in manufacturing processes: a considerable improvement in manufacturing processes was obtained due to the ease of assembly of the harvester.

3. Reduction in design and engineering and manufacturing costs: the new harvester design resulted in a $32 \%$ reduction in the total costs involved in the development of the new product.

The DFM methodology brought great benefits to the case study, the wide tolerances and ease of fabrication of the parts were the biggest benefits of the project, saving time and money. The reduction in the number of components helps save time in drawing generation and assembly analysis. The use of standard commercial components offers the possibility of having spare parts available if needed.

Tables 1, 2, 3 and 4 show the results obtained by applying DFD to the final harvester configuration, which served as the basis for optimizing the final assembly and production process.

\begin{tabular}{|c|c|c|c|}
\hline \multirow[t]{2}{*}{ Concept } & \multicolumn{2}{|c|}{ Design } & Ratio \\
\hline & 1st. Prototype & Redesign & \\
\hline Chassis sub-systems & 19 & 14 & $26 \%$ \\
\hline Components & 82 & 53 & $35 \%$ \\
\hline Manufacturing time & 586 & 419 & --- \\
\hline Disassembly time & 365 & $242 *$ & --- \\
\hline Total time & 951 & 661 & --- \\
\hline
\end{tabular}

Table 1 Design proposal based on DFD: Chassis Source: Own Production

\begin{tabular}{|c|c|c|c|}
\hline \multirow{2}{*}{ Concept } & \multicolumn{2}{|c|}{ Design } & \multirow[t]{2}{*}{ Ratio } \\
\hline & $\begin{array}{l}\text { 1st. } \\
\text { Prototype }\end{array}$ & Redesign & \\
\hline Wagon sub-systems & 18 & 13 & $28 \%$ \\
\hline Components & 92 & 63 & $32 \%$ \\
\hline Manufacturing time & 852 & 684 & -- \\
\hline Disassembly time & 641 & $512 *$ & -- \\
\hline Total time & 1493 & 1196 & --- \\
\hline
\end{tabular}

Table 2 Design proposal based on DFD: Wagon Source: Own Production

OJEDA-ESCOTO, Pedro Agustín. Redesigning a product: Assembly, manufacture and production strategies. Journal of Technological Operations. 2021 


\begin{tabular}{|l|r|r|r|}
\hline \multicolumn{1}{|c|}{ Concept } & \multicolumn{3}{|c|}{ Design } \\
& $\begin{array}{l}\text { 1st. } \\
\text { Prototype }\end{array}$ & \multicolumn{1}{l|}{ Redesign } & \\
\hline Lifting sub-systems & 12 & 9 & $25 \%$ \\
\hline Components & 75 & 58 & $23 \%$ \\
\hline Manufacturing time & 522 & 395 & --- \\
\hline Disassembly time & 346 & $277^{*}$ & --- \\
\hline Total time & 868 & 672 & --- \\
\hline * Estimated times
\end{tabular}

Table 3 Design proposal based on DFD: Lifting Source: Own Production

\begin{tabular}{|l|r|r|r|}
\hline \multicolumn{1}{|c|}{ Concept } & \multicolumn{2}{|c|}{ Design } \\
\hline & $\begin{array}{l}\text { 1st. } \\
\text { Prototype }\end{array}$ & \multicolumn{1}{l|}{ Redesign } & \\
\hline Suspension sub-systems & 5 & 3 & $40 \%$ \\
\hline Components & 19 & 12 & $37 \%$ \\
\hline Manufacturing time & 218 & 180 & --- \\
\hline Disassembly time & 196 & $127 *$ & -- \\
\hline Total time & 414 & 307 & --- \\
\hline
\end{tabular}

Estimated times

Table 4 Design proposal based on DFD: Suspension Source: Own Production

With the results contained in the previous tables, it was possible to integrate the assembly and disassembly procedures of the harvester; likewise, the strategies to align the trailer manufacturing with mass production were defined. These strategies are presented in the following section.

\subsection{Production Alignment Strategies}

Once the new harvester architecture was defined and the product concept was tested, the following strategies were defined to align it with production (Figure 8), taking into account product image and marketing (for confidentiality reasons, these strategies are mentioned in a very global manner) [11].

Product development and prototype evaluation

The first step to think about defining strategies to align a product to production is to corroborate that the product concept passes a commercial test (projection of the customer's special requirement). Once this experience is approved, we move on to the product development stage, during which the development and engineering areas transform the concept into a physical product.

\section{Marketing Strategy}

The development of the marketing strategy refers to the design of an initial strategy for the new product, based on the final concept and involves the following segments:
a. Market share
b. Probable product price
c. Product positioning
d. Sales target

\section{Commercial viability strategy}

Once the final product concept has been defined, is possible to evaluate the commercial attractiveness of the defined proposal. The commercial analysis involves the exploration of sales and costs to determine whether the established objectives will be met.

\section{Market testing strategy}

Once the product has passed the functionality and consumer approval tests, the next step is to bring it to market. Market testing is the phase where the product is introduced to a more realistic market environment.

\section{Marketing strategy}

Market testing provides product managers with the information they need to make the final decision on launching a new product.

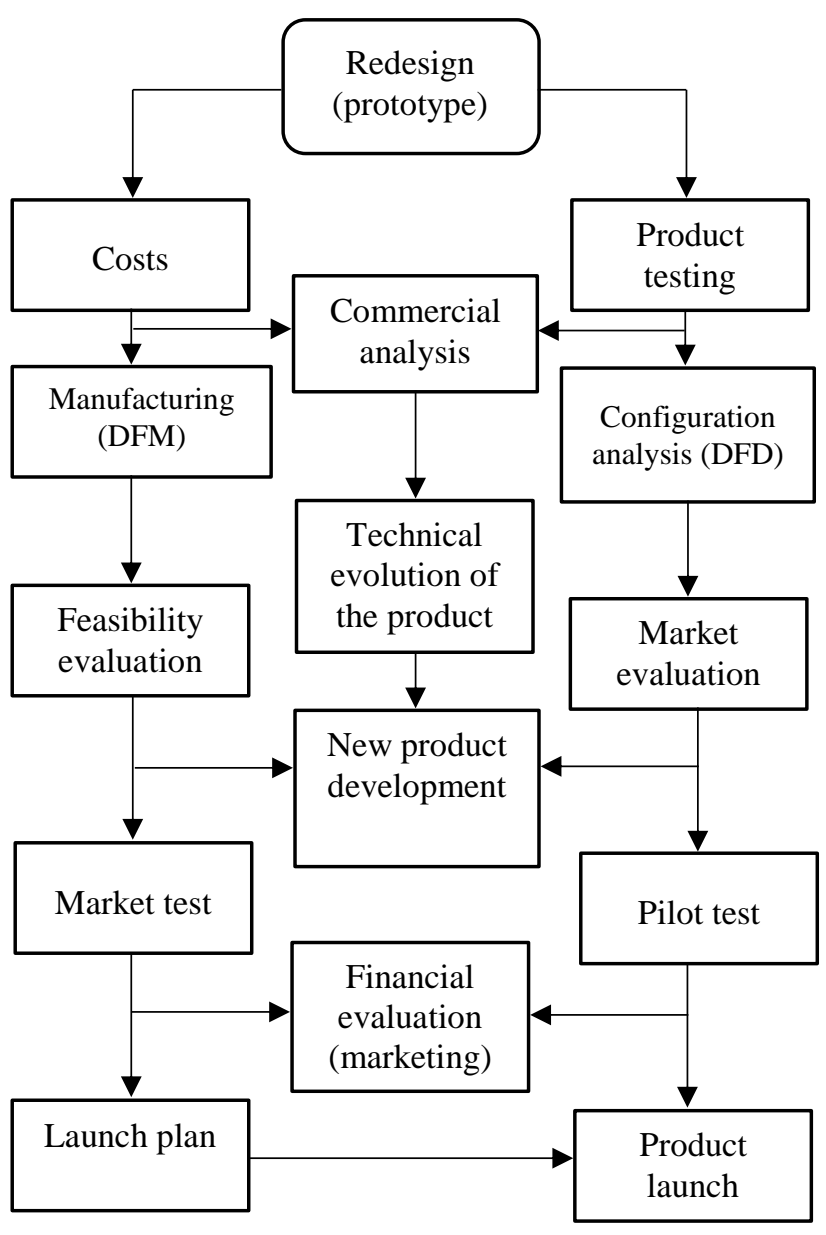

Figure 8 Overall product redesign process Source: Own Production

OJEDA-ESCOTO, Pedro Agustín. Redesigning a product: Assembly, manufacture and production strategies. Journal of Technological Operations. 2021 


\section{Conclusions}

Design is to establish and define pertinent solutions and structures for problems that have not been solved before or new solutions proposed in a different way for problems that have been previously solved. Advances in computational analysis and technology allow engineers and researchers to have effective diagnostic and simulation tools that facilitate, at any given time, the design, redesign or optimization of a mechanical system.

In this work, the optimization of the geometry of a harvester and the results of the application of DFD and DFM criteria were presented as a case study. In order to define a new harvester design, several configurations were proposed and reviewed to solve the studied problem. Several configurations were also conceptualized taking into account the defined approaches and finally the product architecture was generated.

Finally, the strategies defined for the adequacy of the new product developed for production were presented, taking into account sales projections, product image and marketing. The global diagram where these defined strategies were integrated within the complete process of redesigning the new product to align it to mass production was also shown.

\section{Thanks}

The author of this paper is grateful for the technical, economic and logistical support of the Industrial Electromechanics and Energy Division of the Technological University of Aguascalientes.

\section{References}

[1] Ojeda, E.P. Design for Disassembly (DFD): successful case of a product redesign, Proceedings of the XXVI Annual International Congress of SOMIM, 6-1, 2020.

[2] Mule, J.Y. Design for Disassembly Approaches on Product Development, International Journal of Scientific \& Engineering Research, 3-6, 2012.
[3] Won-Shik, C. et al. From design for manufacturing (DFM) to manufacturing for design (MFD) via hybrid manufacturing and smart factory: A review and perspective of paradigm shift, International Journal of Precision Engineering and ManufacturingGreen Technology, 3-2, 2016.

[4] Germani, M., Mandolini, M., Marconi, M., Rossi, M. An approach to analytically evaluate the product disassemblability during the design process, 24th CIRP Design Conference. Elsevier, 21, 2014.

[5] Soh, S.L., Ong, A.K., Nee, A.Y.C. Application of Design for Disassembly from Remanufacturing Perspective, 12th Global Conference on Sustainable Manufacturing, Elsevier, 26, 2015.

[6] Samy, S., ElMaraghy, H. A model for measuring products assembly complexity, International Journal of Computer Integrated Manufacturing, 23-11, 2010.

[7] Krumenauer, F.Z., Matayoshi, C.T., da Silva, I.B., Filho, M.S., Batalha, G.F. Concurrent engineering and DFMA approaches on the development of automotive panels and doors, Journal of Achievements in Materials and Manufacturing Engineering, 31-2, 2008.

[8] Justel, D., Vidal, R, Chiner, M. TRIZ applied to innovate in Design for Disassembly, 13th CIRP International Conference on Life Cycle Engineering, 2006.

[9] Ulrich, K.T., Eppinger, S.D. Product design and development (3rd. ed.), Mc. Graw-Hill, 2004.

[10] Sánchez, C., Cortés, C. Concepts of design for manufacturing (DFM) of lost wax parts, Engineering \& Research Journal, 25-3, 2005.

[11] Ojeda, E.P., López, P.M. Redesign of a product oriented to production, Proceedings of the XXV Annual International Congress of SOMIM, 5-1, 2019.

[12] Ullah, I., Tang, D., Wang, Q., Yin, L., Hussai, I. Managing engineering change requirements during the product development process, Concurrent Engineering Research and Applications. SAGE Publications Journals, 000, 2017. 
[13] Wang, H., Peng, Q., Zhang, J., Gu, P. Selective disassembly planning for the end-oflife product, 27th CIRP Design Conference, Elsevier, 60, 2017.

[14] Ullah, I., Tang, D., Yin, L. Engineering product and process design changes: A literature overview, 9th International Conference on Digital Enterprise Technology, 56, 2016.

[15] Soh, S., Ong, S., Nee, A. Application of Design for Disassembly from Remanufacturing Perspective, 12th Global Conference on Sustainable Manufacturing, Elsevier, 26, 2015. 